\title{
Stillbirth (Co)Variance Components for a Sire-Maternal Grandsire Threshold Model and Development of a Calving Ability Index for Sire Selection
}

\author{
J. B. Cole, ${ }^{1}$ G. R. Wiggans, P. M. VanRaden, and R. H. Miller \\ Animal Improvement Programs Laboratory, Agricultural Research Service, USDA, Beltsville, MD 20705-2350
}

\begin{abstract}
(Co)variance components for stillbirth in US Holsteins were estimated under a sire-maternal grandsire threshold model using subsets of data from the national calving ease database, which includes over 6 million calving records with associated stillbirth scores. Stillbirth was coded as a binomial trait indicating whether the calf was alive $48 \mathrm{~h}$ postpartum. Records were selected for calves whose sire and maternal grandsire (MGS) were among the 2,600 most frequently appearing bulls (2,578 sires and 2,586 MGS). Herd-years were required to contain at least 20 records and only single births were used. After editing, the data set included 2,083,979 calving records from 5,765 herds and 33,304 herd-years. Six sample datasets of approximately 250,000 records each were created by randomly selecting herd codes. Quasi-REML and Bayesian approaches were used to estimate (co)variance components from each sample. The model included fixed yearseason, parity-sex, birth year group of sire, and birth year group of MGS effects and random herd-year, sire, MGS, and residual effects. Quasi-REML and Bayesian analyses produced similar results, although the Bayesian estimates were slightly larger. Marginal posterior means (and standard deviations) from the Bayesian analysis averaged 0.0085 (0.0015), 0.0181 (0.0020), $0.0872(0.0538)$, and $0.00410(0.0001)$ for sire, MGS, and herd-year variances and the sire-MGS covariance, respectively. Mean direct and maternal heritabilities were $0.030(0.003)$ and $0.058(0.005)$, respectively, and the mean genetic correlation between the 2 effects was -0.02 (0.16). A calving ability index combining stillbirth (SB) and calving ease (CE) was developed for inclusion in the Lifetime Net Merit index. The index was calculated as $-4($ sire $\quad \mathrm{CE})-3($ daughter $\quad \mathrm{CE})-4($ sire $\mathrm{SB}$ ) -8 (daughter SB).
\end{abstract}

Received July 7, 2006.

Accepted January 31, 2007.

${ }^{1}$ Corresponding author: jcole@aipl.arsusda.gov
Key words: calving ability index, stillbirth, threshold model, variance component

\section{INTRODUCTION}

Genetic evaluations for calving ease (CE) have been computed in the United States since 1977 (Berger, 1994; Van Tassell et al., 2003), but evaluations are not provided for other calving traits, such as stillbirth (SB). A national evaluation for SB using a sire-maternal grandsire (S-MGS) model was implemented in August 2006 (Cole et al., 2007), and required (co)variance component estimates for the random sire and maternal grandsire (MGS) effects, as well as the covariance between them. Economic values for CE and SB were combined and included in the Lifetime Net Merit (NM\$) index (VanRaden and Multi-State Project S-1008, 2006).

Lifetime Net Merit is a lifetime profit function combining yield, fertility, health, conformation, and longevity. VanRaden (2004) presented a review of the evolution of $\mathrm{NM} \$$ over time as well a comparison of $\mathrm{NM} \$$ with total merit indices used in other countries. Weights on calving traits ranged from 4 to $12 \%$, with the Netherlands and Sweden placing the most emphasis on calving traits and Germany and the United States the least. Germany, the Netherlands, Norway, Sweden, and Switzerland currently include calving traits in their national indices (Interbull, 2006).

Stillborn calves, those born dead or dying within 48 $\mathrm{h}$ of birth, are of increasing concern to US dairy producers. Meyer et al. (2001a) found that the stillbirth rate increased from $9.5 \%$ in 1985 to $13.2 \%$ in 1996, costing producers $\$ 125.3$ million per year. Philipsson (1996) reported that about half of all stillborn calves are born without difficulty, emphasizing the desirability of separate evaluations for dystocia and stillbirth.

Trait definitions vary slightly between countries, with most defining stillbirths as those calves born dead or dying within $24 \mathrm{~h}$ of parturition (Philipsson et al., 1979), although Germany, Israel, and the United States include deaths within $48 \mathrm{~h}$ of birth (Weller et al., 1988; 
Berger et al., 1998; Interbull, 2004). Breed differences play a role in perinatal mortality (Philipsson, 1976; Thompson et al., 1981), and Rossoni et al. (2005) reported that $10 \%$ of Italian Brown Swiss calves did not suckle by the third meal offered postpartum, contributing to increased postnatal mortality. Incidence rates and heritabilities were similar when comparing parities across countries despite differences in trait definition, with the exception of Sweden (Steinbock et al., 2003).

The purpose of this research was to estimate current genetic parameters for an S-MGS model to use in the US national genetic evaluation of SB based on US data (Cole et al., 2007) and to develop a calving ability index (CA\$) for inclusion in NM\$.

\section{MATERIALS AND METHODS}

\section{Genetic Parameters for Stillbirth}

Data. The US national CE database includes over 6 million calving records with associated SB scores for Holstein cows calving since 1980. Stillbirths are reported on a 3 -point scale, with 1,2 , and 3 representing calves born alive, calves born dead, and calves that died within $48 \mathrm{~h}$ of birth, respectively. Scores of 2 and 3 were combined for evaluation. Herds were required to have at least 10 calving records with an SB score of 2 or 3 in the database. Herd-years had to include at least 20 records and only single births were used.

Datasets small enough to be computationally manageable with large contemporary groups were formed for (co)variance components estimation. Records of calvings with unknown MGS were eliminated, and records with sire and MGS among the 2,600 most frequently appearing bulls (2,578 distinct sires and 2,586 distinct MGS) were selected (Wiggans et al., 2003), which favors large herds that use many popular sires. The pedigree file contained 2,994 animals, which included 394 bulls that were not sires or MGS but appeared in the pedigrees of the 2,600 most frequently appearing bulls. Cows were allowed to have more than one calving event in the data, but the inclusion of all records for a cow was not guaranteed. After editing, the data set included 2,083,979 calving records from 5,765 herds and 34,190 herd-years. Six sample datasets of approximately 250,000 records each were created by randomly selecting herd codes without replacement, and records were distinct across datasets. Sample datasets ranged from 239,192 to 286,794 observations, and all averaged $7 \%$ stillbirths.

\section{Model}

The S-MGS threshold model used for parameter estimation was the same as used for the routine national genetic evaluation for SB (Cole et al., 2007):

$$
\mathrm{y}=\mathrm{HY}+\mathrm{YS}+\mathrm{PS}+\mathrm{Y}_{\mathrm{s}}+\mathrm{Y}_{\mathrm{m}}+\mathrm{s}+\mathrm{m}+\mathrm{e}
$$

where $\mathrm{y}=$ unknown liability to $\mathrm{SB}, \mathrm{HY}=$ random herdyear effect, YS = fixed year-season effect, PS = fixed parity-sex effect, $Y_{\mathrm{s}}=$ fixed sire birth year effect, $\mathrm{Y}_{\mathrm{m}}=$ fixed MGS birth year effect, $\mathrm{s}=$ random sire effect, $\mathrm{m}=$ random MGS effect, and e = random residual effect. The residual variance $\left(\sigma_{\mathrm{e}}^{2}\right)$ was assigned a value of 1 . Parities were first, second, and third and later. Yearseason groups began in October and May. Relationships among bulls were ignored for both sire and MGS effects. For widely used sires, relationships would add little to accuracy of the evaluations; however, ignoring paternal half-sib relationships could result in underestimation of genetic variances. (Co)variance components were estimated from the 6 samples of the full data set using quasi-REML (Hoeschele et al., 1995) and Bayesian (Sorensen et al., 1995) procedures as implemented in the CBLUP90REML and THRGIBBS1F90 computer programs (Misztal et al., 2002; Tsuruta and Misztal, 2006).

In the Bayesian analysis, prior distributions were flat for the fixed effects and normal for the sire, MGS, and herd-year effects. Quasi-REML (co)variance components were used as starting values for the Bayesian analysis. One Gibbs chain of 30,000 samples was drawn and the first 10,000 samples were discarded as burnin, and then every sixth sample from the remaining 20,000 samples was included in the summary. Given that only a single threshold was used, and that no trend was observed in plots of the Gibbs samples for each of the random effects, a longer burn-in period was not needed. Heritabilities and correlations were calculated using the posterior means from each of the 6 samples and averaged.

A random herd-year effect was used to avoid the extreme category problem in which all records in a fixed group belong to the same category (Harville and Mee, 1984; Misztal et al., 1989; Luo et al., 2001). This strategy has been successfully used in the US calving ease system for almost $20 \mathrm{yr}$ (Berger, 1994; Van Tassell et al., 2003). Across the 6 sample datasets, $93 \%$ of the records had an SB score of 1 . Of the 34,190 herd-years in the data set, 2,785 (8\%) contained records with only scores of 1 .

The numbers of levels of effects in the sample datasets are shown in Table 1. Bulls were included in the model as both sires and MGS, even if they had no daughter or granddaughter records in the data, to estimate the correlation between the sire and MGS effects. The sire birth year effect had more levels than MGS birth year because recently born sires were not yet MGS. Birth year effects were included in the model to account for change over time and differences between records with and without MGS. 
Table 1. Frequencies of model effects in sample data files

\begin{tabular}{lrrrrrr}
\hline & \multicolumn{5}{c}{ Sample } \\
\cline { 2 - 6 } Effect & \multicolumn{1}{c}{1} & \multicolumn{1}{c}{ } & \multicolumn{1}{c}{4} & \multicolumn{1}{c}{5} & 6 \\
\hline Herd-year & 4,339 & 3,982 & 4,226 & 4,219 & 4,011 & 4,381 \\
Year-season & 51 & 52 & 52 & 52 & 51 & 52 \\
Parity-sex & 6 & 6 & 6 & 6 & 6 & 6 \\
Sire birth year & 18 & 18 & 18 & 18 & 18 & 18 \\
MGS $^{1}$ birth year & 16 & 16 & 16 & 16 & 16 & 16 \\
Sire & 2,994 & 2,994 & 2,994 & 2,994 & 2,994 & 2,994 \\
MGS & 2,994 & 2,994 & 2,994 & 2,994 & 2,994 & 2,994 \\
\hline
\end{tabular}

${ }^{1}$ Maternal grandsire.

Solutions for sire variance $\left(\sigma_{\mathrm{s}}^{2}\right)$, MGS variance $\left(\sigma_{\text {mgs }}^{2}\right)$, and the sire-MGS covariance $\left(\sigma_{\mathrm{s}, \mathrm{mgs}}\right)$ were converted to direct (D) and maternal $(\mathbf{M})$ effects to facilitate comparison of results with literature estimates using derivations from Willham (1972):

$$
\begin{gathered}
\sigma_{\mathrm{D}}^{2}=4 \sigma_{\mathrm{s}}^{2}, \\
\sigma_{\mathrm{D}, \mathrm{M}}=4 \sigma_{\mathrm{s}, \mathrm{mgs}}-2 \sigma_{\mathrm{s}}^{2}, \text { and } \\
\sigma_{\mathrm{M}}^{2}=4 \sigma_{\mathrm{mgs}}^{2}-4 \sigma_{\mathrm{s}, \mathrm{mgs}}+\sigma_{\mathrm{s}}^{2} .
\end{gathered}
$$

The genetic correlation between $\mathrm{D}$ and $\mathrm{M}$ was calculated as:

$$
\mathrm{r}_{\mathrm{D}, \mathrm{M}}=\frac{\sigma_{\mathrm{D}, \mathrm{M}}}{\sqrt{\sigma_{\mathrm{D}}^{2} \sigma_{\mathrm{M}}^{2}}}
$$

The expectation of the phenotypic variance was:

$$
\sigma_{\mathrm{P}}^{2}=\sigma_{\mathrm{s}}^{2}+\sigma_{\mathrm{mgs}}^{2}+\sigma_{\mathrm{e}}^{2}
$$

Using this phenotypic variance, the direct and maternal heritabilities were calculated as:

$$
\mathrm{h}_{\mathrm{D}}^{2}=\frac{\sigma_{\mathrm{D}}^{2}}{\sigma_{\mathrm{P}}^{2}}
$$

and

$$
\mathrm{h}_{\mathrm{M}}^{2}=\frac{\sigma_{\mathrm{M}}^{2}}{\sigma_{\mathrm{P}}^{2}} .
$$

The covariance term $\sigma_{\mathrm{s}, \mathrm{mgs}}$ was not included in the calculation of $\sigma_{\mathrm{P}}^{2}$ because it was assumed that sire and MGS were unrelated, and that sire-daughter matings were rare. Only the genetic and residual (co)variances were used when calculating heritabilities; herd-year variances were not used so that results are more comparable with those from models with fixed contemporary groups.

\section{Calving Ability Index}

The resulting SB (co)variance components, as well as $\mathrm{CE}$ (co)variance components estimated by Wiggans et al. (2003), were used to derive a sire selection index for calving performance. Genetic correlations between $\mathrm{CE}$ and SB were estimated as product-moment correlations between sire PTA for bulls with calving trait reliabilities of at least $90 \%(\mathrm{n}=571)$. The aggregate genotype for CA $\$$ included 4 traits: service sire and MGS CE and SB. Calculation requires subtracting trait means, multiplying by economic values, and reversing sign to obtain net benefit instead of net cost. Expected annual genetic progress for each trait was obtained as the correlation of the trait with $\mathrm{CA} \$$ multiplied by the SD of the trait PTA multiplied by 0.125 , which is the yearly trend in $\mathrm{SD}$ of $\mathrm{CA} \$$.

Proposed US weights for Holsteins were derived as follows. Value of 2-d-old calves was assumed to be $\$ 150$ for bulls and $\$ 450$ for heifers compared with $\$ 100$ for bulls and $\$ 150$ for heifers in $2003 \mathrm{NM} \$$ (VanRaden and Seykora, 2003). Some recent prices have been higher, but in the near future additional females may be produced for $<\$ 400$ using sexed semen (Weigel, 2004). Stillbirth evaluations are expressed as the percentage of calves that die as a difference from the base of $8 \%$. Lifetime value of a $1 \%$ decrease in daughter SB (DSB) is 2.8 lactations multiplied by average calf value: $2.8(\$ 150+\$ 450) / 2(100)=\$ 8.40$. For sire SB (SSB), this value must be halved because SSB measures the full effect of the service sire whereas DSB measures only half of the dam's effect.

The value of daughter CE (DCE) includes $\$ 75$ per difficult birth (CE score 4 or 5 ) for farm labor and veterinary charges, and a $1.5 \%$ increased probability of cow death multiplied by $\$ 1,800$. Those expenses are multiplied by 2 because scores 2 and 3 contribute additional smaller effects that occur more frequently. Difficulty in later parities is 0.3 as great, which results in a lifetime incidence of $1+0.3(1.8)=1.5$. Total value of DCE is $[\$ 70+0.015(\$ 1,800)] \times 2(1.5) / 100=\$ 2.91$. Calv- 
ing ease costs are based primarily on research by Dematawewa and Berger (1997).

The value of sire CE (SCE) also includes losses in the bull's mates of $\$ 100$ for yield and $\$ 75$ for fertility and longevity. Difficult births reduce 305-d milk yield by $317.51 \mathrm{~kg}$ and delay the bull's mates from becoming pregnant again by $20 \mathrm{~d}$ on average. Such losses are not charged to DCE because the bull's daughter evaluations for yield, fertility, and longevity already account for them. The value of SCE must be halved, as with SSB. Total value of SCE is $[\$ 50+0.015(\$ 1,800)+\$ 100+$ $\$ 75] \times 2(1.5) / 2(100)=\$ 3.78$. For calculation of CA $\$$, values were rounded to $\$ 4$ for SCE, $\$ 3$ for DCE, $\$ 4$ for $\mathrm{SSB}$, and $\$ 8$ for DSB.

The economic value used in NM\$ is a weighted average of losses for cows and heifers. Thus, when ranking sires for heifer use, another $\$ 4$ should be subtracted from $\mathrm{NM} \$$ for each percentage of SCE, and $\$ 2$ for each percentage of SCE should be added back to $\mathrm{NM} \$$ when ranking service sires for cows. These minor adjustments for the differing economic values in heifer vs. cow matings can be handled with computerized mating programs. Double-counting of costs associated with CE because it is not removed from SB is avoided by assigning only costs associated with dead calves to SB; $\mathrm{CE}$ expenses include veterinary and labor costs, as well as lost income, but do not include the value of dead calves.

\section{RESULTS AND DISCUSSION}

\section{Modeling of First and Later Parities}

Recent studies (Steinbock et al., 2003; Philipsson et al., 2006) suggest that SB in first and later parities are different traits and should be analyzed separately using a multiple-trait model. A single-trait approach was adopted over a multiple-trait approach because the US evaluation for SB (Cole et al., 2007) is an extension of the single-trait CE evaluation used since 2003 (Van Tassell et al., 2003). The United States also participates in Interbull evaluations for both CE and SB, which do not distinguish between first and later parities in the analyses. Of the 6 countries participating in the Interbull SB evaluation for Holsteins, only the US uses a threshold model (Interbull, 2006).

Although desirable, implementation of a multipletrait threshold model for $\mathrm{CE}$ and $\mathrm{SB}$ is a formidable challenge given the size of the US data set, and the advantage of using a multiple-trait model may be greater than that of a threshold model. Canada has developed a multiple-trait linear model for the evaluation of female fertility traits including CE and SB (Jamrozik et al., 2005) rather than using threshold models for the calving traits. This approach appears promising
Table 2. (Co)variance components from sample data files estimated by Quasi-REML

\begin{tabular}{lcccc}
\hline Sample & $\begin{array}{c}\text { Herd-year } \\
\text { variance }\end{array}$ & $\begin{array}{c}\text { Sire } \\
\text { variance }\end{array}$ & $\begin{array}{c}\text { MGS }^{1} \\
\text { variance }\end{array}$ & $\begin{array}{c}\text { Sire-MGS } \\
\text { covariance }\end{array}$ \\
\hline 1 & 0.072 & 0.008 & 0.016 & 0.004 \\
2 & 0.074 & 0.007 & 0.015 & 0.004 \\
3 & 0.076 & 0.008 & 0.017 & 0.005 \\
4 & 0.072 & 0.007 & 0.017 & 0.004 \\
5 & 0.069 & 0.007 & 0.016 & 0.002 \\
6 & 0.091 & 0.008 & 0.015 & 0.004 \\
Mean & 0.076 & 0.008 & 0.016 & 0.004 \\
\hline
\end{tabular}

${ }^{1}$ Maternal grandsire.

and Wiggans et al. (2006) presented results from a multiple-trait linear model analysis of $\mathrm{CE}$ that were computationally feasible with a large data set. Research to develop a multiple-trait model for the United States that includes CE and SB in first and later parities as correlated traits is ongoing.

\section{Genetic Parameters for Stillbirth}

(Co)variance components from the quasi-REML and Bayesian analyses are presented in Tables 2 and 3, respectively. Those (co)variance components were used to calculate heritability for, and correlations between, direct, maternal, and MGS effects (Table 4).

Direct heritabilities ranged from 0.026 to 0.034 under the Bayesian analysis, and 0.024 to 0.031 in the quasiREML analysis. Maternal heritabilities were higher in both cases, ranging from 0.052 to 0.065 under the Bayesian analysis and 0.046 to 0.057 under quasiREML. Gevrekçi et al. (2006) reported similar results from a Bayesian analysis of a subset of data from the US national CE database. These results are also similar to those of Luo et al. (1999), who reported direct and maternal heritabilities of 0.03 and 0.06 , respectively, for SB in Canadian Holsteins. Jamrozik et al. (2005) reported direct and maternal heritabilities of 0.016 and 0.035 for first parity, and 0.012 and 0.017 for later parities using a multiple-trait linear model. Steinbock et al. (2003) obtained direct and maternal heritabilities of 0.12 and 0.08 using first-parity Swedish Holstein data. Hansen et al. (2004) reported direct and maternal heritabilities of 0.10 and 0.12 , respectively, but their data also included only first-parity cows. The heritabilities calculated in this study are intermediate to those reported for first vs. later parities using threshold models (Steinbock et al., 2003; Hansen et al., 2004), but are larger than those calculated from a subset of the current data using a linear model (Meyer et al., 2001b). This is consistent with expectations, because linear model heritabilities are generally consistent with threshold model estimates when converted from the observed to 
Table 3. Posterior means and standard deviations for (co)variance components from sample data files estimated by Bayesian analysis

\begin{tabular}{|c|c|c|c|c|c|c|c|c|}
\hline \multirow[b]{2}{*}{ Sample } & \multicolumn{2}{|c|}{$\begin{array}{c}\text { Herd-year } \\
\text { variance }\end{array}$} & \multicolumn{2}{|c|}{ Sire variance } & \multicolumn{2}{|c|}{$\mathrm{MGS}^{1}$ variance } & \multicolumn{2}{|c|}{$\begin{array}{l}\text { Sire-MGS } \\
\text { covariance }\end{array}$} \\
\hline & Mean & SD & Mean & SD & Mean & SD & Mean & SD \\
\hline 1 & 0.084 & 0.058 & 0.010 & 0.002 & 0.018 & 0.002 & 0.004 & 0.001 \\
\hline 2 & 0.086 & 0.052 & 0.007 & 0.002 & 0.017 & 0.002 & 0.005 & 0.001 \\
\hline 3 & 0.088 & 0.056 & 0.009 & 0.001 & 0.019 & 0.002 & 0.005 & 0.001 \\
\hline 4 & 0.084 & 0.061 & 0.008 & 0.001 & 0.019 & 0.002 & 0.004 & 0.001 \\
\hline 5 & 0.079 & 0.043 & 0.008 & 0.001 & 0.018 & 0.002 & 0.002 & 0.001 \\
\hline 6 & 0.104 & 0.054 & 0.009 & 0.002 & 0.017 & 0.002 & 0.004 & 0.001 \\
\hline Mean & 0.087 & 0.054 & 0.009 & 0.002 & 0.018 & 0.002 & 0.004 & 0.001 \\
\hline
\end{tabular}

${ }^{1}$ Maternal grandsire.

the underlying scale. The current evaluation could be enhanced in the future by modeling sire and MGS effects in first and later parities separately (Wiggans et al., 2006).

Estimated genetic correlations between direct and maternal effects in Table 4 had means near zero, with estimates ranging from -0.28 to 0.17 , whereas the sireMGS correlations averaged 0.33 and were positive in all cases. A positive correlation was expected a priori because a portion of the direct effect is included in both the sire (1/4) and MGS (1/16) effects. The results in Tables 2 and 3 show that the ratio of $\sigma_{\mathrm{s}, \mathrm{mgs}}$ to $\sigma_{\mathrm{s}}^{2}$ was close to 2:1 for all samples, resulting in a $\sigma_{\mathrm{D}, \mathrm{M}}$ that was near zero. The correlation between the sire and MGS effects is driven largely by the shared direct effect; the magnitude of the sire effect was much smaller for SB than for CE (Wiggans et al., 2003), resulting in a smaller correlation between effects for the former. These results are similar to those of Hansen et al. (2004), who reported a marginal posterior mean directmaternal correlation of 0.06. Steinbock et al. (2003) and Luo et al. (1999) reported correlations of -0.11 and -0.24 , respectively, for direct and maternal effects for first-parity cows. Jamrozik et al. (2005) assumed that correlations between direct and maternal effects were zero for computational limitations. Lower correlations are expected when data from all parities are analyzed together because the genetic correlation between first and later parities is $<1$ (Steinbock et al., 2003).
(Co)variance component estimates were similar between the 2 estimation procedures, although the Bayesian estimates were consistently higher than the quasiREML estimates. This may be due to the fact that the REML estimates are equivalent to posterior modes assuming flat priors (Gianola and Fernando, 1986) rather than posterior means; when the distribution of samples is right-skewed, the posterior mean is larger than the posterior mode. These estimates were larger than those from Meyer et al. (2001b), but the difference is probably attributable to the use of a threshold model rather than a linear model on binary responses. Hansen et al. (2004) obtained much higher (co)variance components estimates using Danish data, but their study included only first-parity Holsteins.

\section{Calving Ability Index}

Means and standard deviations of true transmitting abilities, heritabilities, and economic values of SCE, DCE, SSB, and DSB are shown in Table 5. Correlations among service sire and maternal PTA for SB and CE are presented in Table 6. Stillbirth effects had larger SD than estimated by Meyer et al. (2001b) because in that study effects of $\mathrm{CE}$ and gestation length were removed. The index was calculated as:

$$
\begin{gathered}
\mathrm{CA} \$=-4(\mathrm{SCE}-8)-3(\mathrm{DCE}-8) \\
-4(\mathrm{SSB}-8)-8(\mathrm{DSB}-8) .
\end{gathered}
$$

Table 4. Heritabilities of direct, maternal, and maternal grandsire (MGS) stillbirth effects and directmaternal $\left(\mathrm{r}_{\mathrm{D}, \mathrm{M}}\right)$ and direct-MGS $\left(\mathrm{r}_{\mathrm{D}, \mathrm{MGS}}\right)$ genetic correlations from sample data files

\begin{tabular}{llcccccc}
\hline & & \multicolumn{3}{c}{ Heritability $(\%)$} & & \multicolumn{2}{c}{ Correlation } \\
\cline { 3 - 4 } \cline { 7 - 7 } Method & Statistic & Direct & Maternal & MGS & & $\mathrm{r}_{\mathrm{D}, \mathrm{M}}$ & $\mathrm{r}_{\mathrm{D}, \mathrm{MGS}}$ \\
\hline Bayesian analysis & Mean & 0.030 & 0.058 & 0.065 & -0.02 & 0.33 \\
& Minimum & 0.026 & 0.052 & 0.061 & -0.25 & 0.18 \\
& Maximum & 0.034 & 0.065 & 0.069 & 0.17 & 0.41 \\
Quasi-REML & Mean & 0.027 & 0.051 & 0.058 & 0.00 & 0.34 \\
& Minimum & 0.024 & 0.046 & 0.054 & -0.28 & 0.20 \\
& Maximum & 0.031 & 0.057 & 0.063 & 0.16 & 0.40 \\
\hline
\end{tabular}


Table 5. Means, SD, heritabilities, economic values, correlations with the calving ability index (CA\$), and expected genetic progress of sire calving ease (SCE), daughter calving ease (DCE), sire stillbirth (SSB), and daughter stillbirth (DSB) ${ }^{1}$

\begin{tabular}{lllll}
\hline & SCE & DCE & SSB & DSB \\
\hline Mean & 8 & 8 & 8 & 8 \\
Standard deviation & 1.7 & 1.4 & 1.0 & 1.7 \\
Heritability (\%) & 0.086 & 0.048 & 0.030 & 0.065 \\
Economic value (\$) & -4.00 & -3.00 & -4.00 & -8.00 \\
Correlation with CA $\$$ & -0.69 & -0.77 & -0.64 & -0.85 \\
Annual change in PTA $^{2}$ & -0.15 & -0.14 & -0.08 & -0.18 \\
\hline
\end{tabular}

${ }^{1}$ The heritability of maternal stillbirth is that of the maternal grandsire effect which is included in the national genetic evaluation model, not that of the pure maternal effect.

${ }^{2}$ Expected genetic progress from selection for Lifetime Net Merit (NM\$) expressed as annual change in PTA.

The units of CA $\$$ are the lifetime dollar value that the calving traits contribute to $\mathrm{NM} \$$. The $\mathrm{CA} \$$ index has a genetic correlation of 0.85 with the combined SCE and DCE values in $2003 \mathrm{NM} \$$ and 0.77 with DCE in the Holstein Association Type-Production Index (TPI; Holstein Association USA, 2005; unpublished data). Thus, SB evaluations can provide additional value beyond that of CE. A preliminary study (Berger et al., 1998) reported less benefit because only service sire effects were examined. Correlations of calving traits to $\mathrm{CA} \$$, and expected annual change in PTA, are presented in Table 5.

For Brown Swiss, economic values were -6 for SCE and -8 for DCE because separate SB evaluations were not available and $\mathrm{CE}$ values included the correlated response in SB. Breeds without $\mathrm{CE}$ or SB evaluations will be assigned a CA $\$$ of 0 . Standard deviations of true transmitting abilities were 1.7 for SCE, 1.4 for DCE, 1.0 for SSB, and 1.7 for DSB with corresponding relative emphasis of $25,15,15$, and $45 \%$ in $\mathrm{CA} \$$. The SD of the index was $\$ 20$ and the relative emphasis on calving traits in $\mathrm{NM} \$$ increased to $6 \%$.

Relative weights for $\mathrm{CE}$ and $\mathrm{SB}$ in calving ability indices of Interbull participants are shown in Table 7. Daughter calving ease is the only calving trait currently included in TPI. The comparatively high weight on DSB in $\mathrm{CA} \$$ is attributable to modeling differences and its

Table 6. Estimated genetic correlations among the traits in the calving ability index ${ }^{1}$

\begin{tabular}{lllll}
\hline Trait & SCE & DCE & SSB & DSB \\
\hline SCE & 1.00 & 0.46 & 0.67 & 0.25 \\
DCE & & 1.00 & 0.29 & 0.63 \\
SSB & & & 1.00 & 0.28 \\
DSB & & & & 1.00 \\
\hline
\end{tabular}

${ }^{1} \mathrm{SCE}=$ sire calving ease, $\mathrm{DCE}=$ daughter calving ease, $\mathrm{SSB}=$ sire stillbirth, DSB = daughter stillbirth. large genetic standard deviation relative to other countries. Weights on maternal effects would be larger for countries using animal models if half of the direct effect was included as in S-MGS models. Denmark publishes a birth index including the 2 paternal traits and a calving index including the 2 maternal traits, but includes only $\mathrm{CE}$ as $6 \%$ of total merit. Relative weights are those currently used, with the exception of the proposed Swiss index of Egger-Danner et al. (1999).

The CA $\$$ index is a component of $\mathrm{NM} \$$, which measures additional lifetime profit that is expected to be transmitted to an average daughter, but does not include additional profit that will be expressed in granddaughters and more remote descendants. Sire SB effects are expressed earlier than DSB effects, which is not accounted for in CA $\$$. Gene flow methods and discounting of future profits could provide a more complete summary of the total profit from all descendants, as well as account for the fact that incomes and expenses are incurred across the lifetime of a cow, not at a single point in time (McClintock and Cunningham, 1974; Wolfová and Nitter, 2004).

\section{CONCLUSIONS}

(Co)variance estimates from this study were used in the implementation of a sire-MGS model for SB for United States Holsteins. The sire-MGS model provides evaluations that include both direct (sire) and maternal SB effects and adjusts sire effects for differences in the maternal SB ability of their mates. Heritability estimates were similar to, but slightly lower, than previous literature estimates. The genetic correlation between direct and maternal effects was much smaller than previous reports. The low genetic correlations between $\mathrm{CE}$ and $\mathrm{SB}$ indicate that SB evaluations can provide additional value beyond that of $\mathrm{CE}$.

Selection on NM $\$$ including CA $\$$ with $6 \%$ of emphasis could reduce PTA for SSB and DSB by 0.8 and 1.1 SD, respectively, per decade. This would reduce the mean PTA for SSB to $7.2 \%$ and for DSB to $6.2 \%$ compared with the current base of $8 \%$. Selection of bulls based on $\mathrm{NM} \$$ will result in lower, but still desirable, rates of gain. Lifetime profitability per cow will improve by $\$ 2.50$ per year from the contribution of $\mathrm{CA} \$$ to $\mathrm{NM} \$$. Mating programs can avoid some losses by assigning bulls with low and high PTA for sire calving traits to heifers and cows, respectively, but direct selection will provide permanent gains.

\section{ACKNOWLEDGMENTS}

The authors gratefully acknowledge Ignacy Misztal and Shogo Tsuruta at the University of Georgia for 
Table 7. Relative weights in calving trait indices of Interbull participants and their emphasis in total merit

\begin{tabular}{|c|c|c|c|c|c|c|}
\hline \multirow[b]{2}{*}{ Country } & \multicolumn{2}{|c|}{ Calving ease } & \multicolumn{2}{|c|}{ Stillbirth } & \multirow[b]{2}{*}{ Model } & \multirow{2}{*}{$\begin{array}{c}\text { Total } \\
\text { merit } \%\end{array}$} \\
\hline & Paternal $^{1}$ & Maternal & Paternal & Maternal & & \\
\hline Germany & 19 & 26 & 26 & 29 & Animal & 7 \\
\hline The Netherlands & 33 & 17 & 33 & 17 & Sire-MGS ${ }^{2}$ & 7 \\
\hline Norway & 0 & 34 & 33 & 33 & Sire-MGS & 3 \\
\hline Sweden & 12 & 38 & 12 & 38 & Sire-MGS & 12 \\
\hline Switzerland & 12 & 12 & 38 & 38 & Animal & 0 \\
\hline USA 2003 & 55 & 45 & 0 & 0 & Sire-MGS & 4 \\
\hline USA 2006 & 25 & 15 & 15 & 45 & Sire-MGS & 6 \\
\hline
\end{tabular}

${ }^{1}$ The meaning of direct and maternal effects differs among countries. Paternal effects typically refer to direct sire effects, while maternal effects may refer to either true maternal or maternal grandsire (MGS) effects.

${ }^{2}$ The Netherlands uses a sire-MGS model in its evaluation but reports a pure maternal effect, rather than a maternal grandsire component that includes both maternal and direct effects (Interbull, 2005).

valuable discussions and use of the CBLUP90REML and THRGIBBS1F90 computer programs. Three anonymous reviewers are thanked for their helpful comments and suggestions.

\section{REFERENCES}

Berger, P. J. 1994. Genetic prediction for calving ease in the United States: Data, models, and use by the dairy industry. J. Dairy Sci. 77:1146-1153.

Berger, P. J., J. R. Thompson, and C. G. Sattler. 1998. Preliminary investigations on the feasibility of a stillbirth evaluation in the USA. Interbull Bull. 18:28-30.

Cole, J. B., G. R. Wiggans, and P. M. VanRaden. 2007. Genetic evaluation of stillbirth in United States Holsteins using a sire-maternal grandsire threshold model. J. Dairy Sci. 90:2480-2488.

Dematawewa, C. M. B., and P. J. Berger. 1997. Effect of dystocia on yield, fertility, and cow losses and an economic evaluation of dystocia scores for Holsteins. J. Dairy Sci. 80:754-761.

Egger-Danner, C., A. William, J. Sölkner, and E. Gierzinger. 1999. Optimisation of progeny testing schemes when functional traits play an important role in the total merit index. Interbull Bull. 23:193-200.

Gevrekçi, Y., Y. M. Chang, K. Kizilkaya, D. Gianola, K. A. Weigel, and Y. Akbass. 2006. Bayesian inference for calving ease and stillbirth in Holsteins using a bivariate threshold sire-maternal grandsire model. Commun. 01-26 in Proc. 8th World Congr. Genet. Appl. Livest. Prod., Belo Horizonte, Brazil.

Gianola, D., and R. L. Fernando. 1986. Bayesian methods in animal breeding theory. J. Anim. Sci. 63:217-244.

Hansen, M., M. S. Lund, J. Pedersen, and L. G. Christensen. 2004. Genetic parameters for stillbirth in Danish Holstein cows using a Bayesian threshold model. J. Dairy Sci. 87:706-716.

Harville, D. A., and R. W. Mee. 1984. A mixed-model procedure for analyzing ordered categorical data. Biometrics 40:393-408.

Hoeschele, I., B. Tier, and H.-U. Graser. 1995. Multiple-trait genetic evaluation for one polychotomous trait and several continuous traits with missing data and unequal models. J. Anim. Sci. 73:1609-1627.

Holstein Association USA. 2005. TPI Formula - December 2005 http://www.holsteinusa.com/html/ss_tpi_formula.html Accessed March 9, 2006.

Interbull. 2004. Description of National Genetic Evaluation System (Germany). http://www-interbull.slu.se/national_ges_info2/ forms/deu/form_ca_deu_hol_jer_ays_041004.pdf Accessed May 25,2006 .

Interbull. 2005. Description of National Genetic Evaluation System (The Netherlands). http://www-interbull.slu.se/national_ges_ info2/forms/nld/form ca nld_all_050201.pdf Accessed May 25, 2006.

Interbull. 2006. Description of national genetic evaluation systems for dairy cattle traits as applied in different Interbull member countries. http://www-interbull.slu.se/national_ges_info2/ framesida-ges.htm Accessed Dec. 15, 2006.

Jamrozik, J., J. Fatehi, G. J. Kistemaker, and L. R. Schaeffer. 2005. Estimates of genetic parameters for Canadian Holstein female reproduction traits. J. Dairy Sci. 88:2199-2208.

Luo, M. F., P. J. Boettcher, J. C. M. Dekkers, and L. R. Schaeffer. 1999. Bayesian analysis for estimation of genetic parameters of calving ease and stillbirth for Canadian Holsteins. J. Dairy Sci. 82:1848-1858.

Luo, M. F., P. J. Boettcher, L. R. Schaeffer, and J. C. M. Dekkers 2001. Bayesian inference for categorical traits with an application to variance component estimation. J. Dairy Sci. 84:694-704.

McClintock, A. E., and E. P. Cunningham. 1974. Selection in dual purpose cattle populations: Defining the breeding objectives. Anim. Prod. 18:237-247.

Meyer, C. L., P. J. Berger, K. J. Koehler, J. R. Thompson, and C. G. Sattler. 2001a. Phenotypic trends in incidence of stillbirth for Holsteins in the United States. J. Dairy Sci. 84:515-523.

Meyer, C. L., P. J. Berger, J. R. Thompson, and C. G. Sattler. 2001b. Genetic evaluation of Holstein sires and maternal grandsires in the United States for perinatal survival. J. Dairy Sci. 84:12461254

Misztal, I., D. Gianola, and J. L. Foulley. 1989. Computing aspects of a nonlinear method of sire evaluation for categorical data. J. Dairy Sci. 72:1557-1568.

Misztal, I., S. Tsuruta, T. Strabel, B. Auvray, T. Druet, and D. H. Lee. 2002. BLUPF90 and related programs. Pages 33:743-744 in Proc. 7th World Congr. Genet. Appl. Livest. Prod., Montpelier, France.

Philipsson, J. 1976. Studies on calving difficulty, stillbirth, and associated factors in Swedish cattle breeds. I. General introduction and breed averages. Acta Agric. Scand. 26:151-164.

Philipsson, J. 1996. Strategies to reduce problems in calving performance and stillbirths by selection and differential use of bulls. Interbull Bull. 12:65-71.

Philipsson, J., J. L. Foulley, J. Lederer, T. Liboriussen, and A. Osinga 1979. Sire evaluation standards and breeding strategies for limiting dystocia and stillbirth. Report of an EEC/EAAP Working Group. Livest. Prod. Sci. 6:111-127.

Philipsson, J., L. Steinbock, and K. Johansson. 2006. Differences in genetic variation of calving traits in Swedish Holstein and Swedish Red cattle. Commun. 01-24 in Proc. 8th World Congr. Genet. Appl. Livest. Prod., Belo Horizonte, Brazil.

Rossoni, A., C. Nicoletti, S. Ghiroldi, E. Santus, and A. Bagnato. 2005. Calf's suckling ability in Italian Brown Swiss. Interbull Bull. 33:218-221. 
Sorensen, D., S. Andersen, D. Gianola, and I. Korsgaard. 1995. Bayesian inference in threshold models using Gibbs sampling. Genet. Sel. Evol. 27:229-249.

Steinbock, L., A. Näsholm, B. Berglund, K. Johansson, and J. Philipsson. 2003. Genetic effects on stillbirth and calving difficulty in Swedish Holsteins at first and second calving. J. Dairy Sci. 86:2228-2235.

Thompson, J. R., A. E. Freeman, P. J. Berger, and M. L. Martinez. 1981. A survey of dystocia and calf mortality in five dairy breeds. J. Dairy Sci. 64(Suppl. 1):81. (Abstr.)

Tsuruta, S., and I. Misztal. 2006. THRGIBBS1F90 for estimation of variance components with threshold-linear models. Commun. 2731 in Proc. 8th World Congr. Genet. Appl. Livest. Prod., Belo Horizonte, Brazil.

Van Tassell, C. P., G. R. Wiggans, and I. Misztal. 2003. Implementation of a sire-maternal grandsire model for evaluation of calving ease in the United States. J. Dairy Sci. 86:3366-3373.

Van Raden, P. M. 2004. Invited Review: Selection on net merit to improve lifetime profit. J. Dairy Sci. 87:3125-3131.

VanRaden, P. M., and Multi-State Project S-1008. 2006. Net merit as a measure of lifetime profit: 2006 revision. http://aipl.arsusda.gov/ reference/nmcalc-2006.htm Accessed June 13, 2006.
VanRaden, P. M., and A. J. Seykora. 2003. Net merit as a measure of lifetime profit: 2003 revision. http://aipl.arsusda.gov/reference/ nmcalc.htm Accessed March 9, 2006.

Weigel, K. A. 2004. Exploring the role of sexed semen in dairy production systems. J. Dairy Sci. 87(E Suppl.):E120-E130.

Weller, J. I., I. Misztal, and D. Gianola. 1988. Genetic analysis of dystocia and calf mortality in Israeli-Holsteins by threshold and linear models. J. Dairy Sci. 71:2491-2501.

Wiggans, G. R., I. Misztal, and C. P. Van Tassell. 2003. Calving ease (co)variance components for a sire-maternal grandsire threshold model with calving ease data. J. Dairy Sci. 86:1845-1848.

Wiggans, G. R., C. P. Van Tassell, J. B. Cole, and L. L. M. Thornton. 2006. Genetic correlations between first and later parity calving ease in a sire-maternal grandsire model. Commun. 01-92 in Proc. 8th World Congr. Genet. Appl. Livest. Prod., Belo Horizonte, Brazil.

Willham, R. L. 1972. The role of maternal effects in animal breeding: III. Biometrical aspects of maternal effects. J. Anim. Sci. 35:1288-1292.

Wolfová, M., and G. Nitter. 2004. Relative economic weights of maternal versus direct traits in breeding schemes. Livest. Prod. Sci. 88:117-127. 